\title{
The impact of physical, neurological and cognitive deficits on risk of falls in people with type 2 diabetes mellitus: a review
}

\author{
Asha H Wettasinghe ${ }^{1}$ Dilshani WN Dissanayake ${ }^{2}$ Lara Allet $^{3,4}{ }^{4}$ rasad Katulanda ${ }^{5}$ Stephen R Lord ${ }^{6}$ \\ 1Department of Allied Health Sciences, Faculty of Medicine, University of Colombo, Sri Lanka (asha@med.cmb.ac.lk) \\ 2Department of Physiology, Faculty of Medicine, University of Colombo, Sri Lanka \\ ${ }^{3}$ Department of Physiotherapy, HES-SO University of Applied Sciences and Arts of Western Switzerland, Geneva, Switzerland; \\ ${ }^{4}$ Department of Internal Medicine Specialties, Department of Internal Medicine, Rehabilitation and Geriatrics, University \\ Hospitals and University of Geneva, Geneva(lara.allet@hcuge.ch) \\ ${ }^{5}$ Department of Clinical Medicine, Faculty of Medicine, University of Colombo, Sri Lanka \\ ${ }^{6}$ Neuroscience Research Australia, UNSW, Randwick, Sydney, Australia
}

\section{Abstract}

There is an increasing prevalence of diabetes mellitus (DM) and diabetic peripheral neuropathy (DPN) in older people in many countries across the world. Older adults with type $2 \mathrm{DM}$ have a significantly higher incidence of falls compared with their counterparts without DM. This review synthesize published findings on sensorimotor, cognitive, balance and mobility impairments, and their associations with falls in people with DM and DPN. Given the high incidence of falls and resulting serious consequences, systematically assessing fall risk in people with DM may optimize fall prevention strategies and reduce the associated morbidity, mortality and the rehabilitation costs for people with these conditions. These findings indicate balance, gait, sensorimotor and cognitive assessments should be administered to DM patients, especially in those with DPN, to document impairment levels and target interventions to reduce falls and associated morbidity, mortality and rehabilitation costs.

Keywords: accidental falls; fall risk; diabetes mellitus; diabetic peripheral neuropathy; physical, neurological and cognitive factors

Correspondence e mail: asha@med.cmb.ac.lk

ORCID ID: https://orcid.org/0000-0002-2835-800X

Copyright: This is an open-access article distributed under the terms of the Creative Commons Attribution License, which permits unrestricted use, distribution, and reproduction in any medium, provided the original author and source are credited (CC BY 4.0)

\author{
Abbreviations: \\ WHO- World health organization \\ DM- Diabetes mellitus \\ DPN- Diabetic peripheral neuropathy \\ US\$- United States dollar
}

\section{Introduction}

Falls are a serious public health issue that contributes to substantial morbidity and mortality in older people. A fall for many people has adverse consequences, including loss of independent living and decreased functioning in daily life. Physical consequences can include minor injuries such as lacerations, bruises, abrasions, and other soft tissue injuries or major injuries such as lacerations requiring suture, dislocations, sprains, and fractures. WHO data indicate 37.3 million falls occur each year that are severe enough to require medical attention (1), resulting in an enormous economic burden. For example, WHO data indicate the average cost per fall injury is US $\$ 3611$ in the Republic of Finland and US\$1049 in Australia, for people aged 65 years or older (1). Finally, falls are the second leading cause of accidental or unintentional injury deaths worldwide (1). The WHO 
estimated that 646,000 individuals die from falls each year, and of these more than $80 \%$ occur in low and middle income countries (1).

Diabetes mellitus (DM) in older people is also a major health care problem. WHO data indicates global prevalence of diabetes among adults over 18 years of age $8.5 \%$ in 2014 (2). DM affects approximately $16.1 \%$ of people aged over 65 years in 1999 (3) and has major impacts on sufferers and health care systems. The total estimated cost of DM in United States for diagnosed diabetes in 2017 is $\$ 327$ billion, which include \$237 billion for direct medical costs and $\$ 90$ billion due to reduced productivity ${ }^{(4)}$. It is estimated that 366 million people had DM in 2011, by 2030 this would have risen to 552 million with changing demography and higher rates of diagnosis (5).

DM is a reported risk factor for falls $(6,7)$. The annual prevalence of falls in people with DM is estimated to be $35 \%$ for those over 55 years ${ }^{(8)}$ and 39\% for those over 65 years ${ }^{(9)}$. Tilling, Darawil, \& Britto (9) also found a high rate of falls in patients with DM and especially in those with poorly controlled diabetes and associated complications, and Chiba at al. reported older people with type $2 \mathrm{DM}$ to be twice as likely to suffer falls compared to control subjects (10).

Diabetic peripheral neuropathy (DPN) is a common late chronic complication and a major factor that reduces quality of life of people with DM (11). DPN affects up to $50 \%$ of people with DM and usually starts with damage to the peripheral sensory nerves which progresses to motor and autonomic nerves $(12,13)$. It causes progressive loss of vibratory, thermal, tactile, and proprioceptive sensitivities (14), and these deficits can impair postural control, with several studies reporting a significant association between DPN severity and risk of falls $(15,16)$. In fact, one study reported people with DPN are 15 times more likely to experience a fall compared to healthy controls (17). Several studies have explored reasons for increased fall risk in people with DM, with several reporting a high prevalence of balance and gait impairments $(18,19)$. However, a recent review (20), has also emphasized the importance of establishing the relationships between DM-related declines in sensorimotor and cognitive systems and falls. The objective of this review is to synthesize physical, neurological and cognitive fall risk factors in people with DM and DPN. This information would be valuable for identifying key test measures for inclusion in fall risk assessments for these groups.

\section{Method}

The two main key words used for the literature search were Diabetes mellitus AND falls. Additional keywords used included "diabetic neuropathy", "balance", "gait", "strength", "cognitive impairment", "sensory impairment" or "risk of falls". The following databases were searched: PubMed, Medline (Web of Science), Medline Ovid and Google scholar. A manual search was also performed using the reference lists of included articles in order to obtain additional articles. Searches were limited to articles in the English Language, published between 1975 and 2019.

\section{Results and Discussion}

Six thousand seven hundred articles containing both DM and fall risk factors were identified. From these, nonrelevant articles were excluded, based on title and abstract screening performed independently by the first two authors. Pilot studies, short communications, duplications, articles not published in peer review journals, and articles not written in English were excluded at this stage. One hundred and sixty eight articles were considered relevant and of these, sixty seven articles were considered to be suitable and of sufficient scientific quality to merit inclusion in this narrative review.

\section{Sensation}

The peripheral nervous system in people with DM is affected by distal and sensory predominant nerve fiber degeneration, axonal loss and endoneurial microangiopathy (21, 22). Delayed nerve conduction is the earliest functional change and segmental demyelization caused by damage to Schwann cells is the earliest histological change in DPN (23). Both small and large diameter neural fibers are affected in DPN (24). Large fibers are affected in the later stages of the disease and result in muscle atrophy, musculoskeletal impairments and autonomic dysfunction (25). Although the axons are preserved in early stages, irreversible axonal degeneration develops later on. The feet are mostly affected by sensory and motor complications in diabetic people (26). The superficial nerves and the deep peroneal, sura and medial plantar nerves, in that sequence, are the first to be affected (27). This can lead to reduced ankle range of motion and deformation of the feet (28). Other common symptoms of DPN are tingling, pain, numbness and weakness in the feet and hands (29). DPN leads to the loss of distal proprioception and impaired muscle and autonomic functions, leading to instability (30). 


\section{Strength}

Older people with DM, both with and without DPN, have decreased maximal lower limb muscle strength and this is associated with impaired mobility (31, 32). Andreassen, Jakobsen \& Andersen (32) found that ankle muscle strength was significantly reduced in people with DPN when compared with matched non-neuropathic and asymptomatic controls with neuropathy, further it has been reported that decreased ankle dorsiflexion strength is a risk factor for falls in people with DM (8).

People with DPN are less able to quickly generate muscle force and have altered muscle activation timings at the ankle and knee compared to control subjects during stair climbing and descending (33); possibly due to a combination of reduced sensory and motor function as a result of polyneuropathy (33).

Atrophy of the ankle extensor and the tibialis anterior muscles and alteration of the collagen structure in the fasciae and muscle tendons due to collagen glycosylation significantly impair muscle strength (34). Weak intrinsic foot muscles with a resultant imbalance between flexors and extensors of the toes are also thought to be responsible for most of the lower extremity complications of people with DM (35). DPN can also lead to foot disarrangement, flat feet (36) and foot ulceration (37).

\section{Cognitive impairment}

Cognition comprises several domains including executive functions, processing speed, attention, psychomotor speed, memory and visuospatial function. Among these, executive functions, speed of processing and psychomotor speed are significantly associated with falls in older adults $(38,39)$. In addition, executive function is a predictor of falls and fall-related risk factors (40). Approximately $60 \%$ of cognitively impaired older adults fall each year, twofold more than that observed among cognitively intact older adults $(41,42)$. High rates of falls among people with dementia with intact motor performances emphasize the importance of impaired cognition as a risk factor for falls (43).

The prevalence of dementia is higher in people with DM than non-DM subjects (44), and it has been suggested that glucose metabolism abnormalities including hyperglycemia and hypoglycemia, and insulin action abnormalities such as insulin deficiency and insulin resistance are related with cognitive impairment in people with DM (44).

People with type $2 \mathrm{DM}$ have reduced performance in several cognitive domains: psychomotor speed (45), frontal lobe/executive function (45, 46), verbal memory (47), processing speed (47), complex motor functioning (45), working memory (46), immediate and delayed recall (48), verbal fluency (45), visual retention (49), and attention (50). Rucker et al. (51) found that verbal, visuospatial and multitasking measures of executive function were significantly impaired in adults with DPN. People with DPN may also have an increased risk for global cognitive decline, impairment of verbal short term memory, delayed recall and visual retention of information (52). However, Moreira et al. (53) suggested that these cognitive impairments are not related to the presence and/or severity of DPN as no difference in all cognitive tests could be found between people with and without DPN. In addition no correlation was found among neuropathy disability score (NDS), neuropathy symptom score (NSS) and any of the cognitive assessments (53).

Cognitive impairment is associated with multiple falls in people with DM (10). However, in a recent review, Hewston and Deshpande (20) contend diabetes-related declines in cognition have not yet been adequately examined as causal factors for increased fall risk in older people with DM. It is unclear which component of cognition should be tested, or whether a disease specific diagnosis such as dementia or mild cognitive impairment, or measures of global cognitive functions or specific cognitive domains such as executive functions would be more useful in a fall risk assessment (43).

\section{Balance}

Balance performance depends on the interaction of multiple sensory, motor, and integrative systems. The primary contributors to stability are hand and foot reaction time, vestibular function (visual field dependence), vision (visual acuity, contrast sensitivity), peripheral sensation (tactile sensitivity, vibration sense, proprioception), and muscle force (knee flexion and extension, ankle dorsiflexion) (54). Aging causes the deterioration of all these physiological functions; hence the risk of falls increases in older adults (55). In addition to the normal aging process, DM and DPN further deteriorate sensory, motor and integrative systems function, further increasing the risk of falls. People with $\mathrm{DM}$, both with and without DPN, have deficits in postural control and functional strength compared with age-matched healthy controls (56).Poor balance has been identified as a strong risk factor for falls in people with DM and DPN (18), with impairments in somatosensory, visual, vestibular systems and cognitive impairment considered major reasons for impaired balance in elderly people with DPN (4). Further, a lack of sensory feedback cueing may occur in DPN which contributes to reduced postural control (18). DPN patients tend to adopt a rigid postural control strategy once they perceive increased sway (18), and this adaptive strategy is associated with the level of neuropathy and history of DM (18). 
DPN people are more prone to falls while walking, indicating they have poorer dynamic balance than control subjects (57). Brown et al. (58) found balance is reduced in people with DPN during level ground walking, stair ascent and stair descent, and noted maximum and range of separations of center of mass from center of pressure in the medial-lateral plane during activities of stair descent, stair ascent, and level walking in DPN patients compared to controls (58). Interestingly, there was no difference in separations of center of mass from center of pressure detected in people with DM engaged in the above activities (58). This may help explain why the DPN patients have impaired lateral balance and an increased number of sideways falls.

Loss of proprioception inputs may directly affect the ability to stabilize body equilibrium during quite stance and when experiencing unexpected perturbations $(54,55)$. Postural sway is increased in people with DPN especially when the eyes are closed (56, 59). In fact, Lafond et al. (60) have found postural sway with eyes open in elderly diabetic neuropathy people is comparable to postural sway with eyes closed of healthy adults. It has also been reported lateral, but no anteroposterior, sway is significantly increased in people with DM and diabetic neuropathy compared to control subjects. And that DPN patients tend to use hip strategies rather than the ankle strategies for balance tests when they are deprived of visual inputs (61).

Finally, a study by Ghanavati et al. (62) indicates people with DPN have significantly decreased functional balance contributing to falls during activities of daily living (62). They found that compared with healthy peers, people with DPN performed significantly worse in the Berg balance tasks of single leg stance, tandem standing and forward reaching, standing unsupported with feet together, sit to stand, stand to sit, transfers, standing unsupported with closed eyes, and placing the alternative foot on step while standing unsupported.

\section{$5 \quad$ Gait}

Older adults with DM have altered gait patterns, especially if they have developed DPN, and this leads to an increased risk of falls (19). During gait, planter flexion peak torques and ankle range of motion in people with DPN are reduced compared to aged matched healthy controls (63). Joint mobility in trunk and lower limb are similarly reduced in people with DM, with or without DPN in each gait plane (64). People with DM have reduced lower limb joint ranges that are more pronounced in people with DPN (52). Joint moment and velocity are also significantly impaired in both groups (64), time pattern changes of the forces transmitted through the foot and increases in the vertical forces through the heel is altered in people with DPN (65).
Even though people with DPN exhibit a more conservative gait pattern, they have an impaired ability to stabilize their body when walking on irregular surfaces that might further increase their risk of falling ${ }^{(66) \text {. }}$

People with DM exhibit significantly slower walking velocity with a wider stance both in linear walking and when turning (67). Slower walking speed has been found to be a strong predictor of falls (8). Decreased lower limb isometric maximal strength, fear of falling and the severity of neuropathy may explain the slower gait speed of people with DM (68). DPN people adopt a slower walking pattern and show an increase in locomotor variability compared to controls (69). However, it has been suggested this increase in gait variability is associated with self-selected walking speed and not directly related to sensory loss (69).

A recent review by Mustapa et al. (4) investigated gait and postural characteristics inherent to DPN people. Gait analysis showed that people with DPN have smaller step lengths, reduced duration of single support, higher duration of double support, decreased gait velocity, lowered cadence, increased step width-to-step length ratio, increased step time and step time variability and greater gait variability (4). Gait patterns in people with DPN, DM without DPN and healthy individuals have also been investigated in real life conditions (68). Irrespective of presence or absence of DPN, people with DM demonstrated decreased gait capacity and increased fall risk (68). Finally, it was found that both physiological (strength and proprioception) and cognitive-behavioral factors (fear of falling) are associated with gait changes in DM people; factors that should be considered when developing fall prevention programs (70).

\section{Conclusions}

DM impairs lower limb sensation, balance, gait and cognitive processing and is a significant risk factor for falls. People with DPN have impaired dynamic and functional balance with increased mediolateral sway in this group identified as a risk factor for sideway falls. Gait changes of people with DM are associated with physical (strength and proprioception), cognitive-behavioral factors (fear of falling) and DPN severity. Thus fall prevention programs should focus not only on physical factors, but also on cognitive and neurological factors. DM people would benefit from an assessment of their risk of falling using an assessment tool which specifically addresses DPN severity, balance, gait and cognitive processing. The development of a fall risk assessment tool for people with DM may be of particular benefit, not only for identifying those at risk of falling, but also for documenting the degree of impairments across the multiple domains affected by DM. Further studies should also focus on identifying the cognitive domains most 
affected by DM and DPN with the aim of including with appropriate cognitive tests within the fall risk assessment tool. Such systematic assessment of fall risk may optimize fall prevention strategies and reduce the associated morbidity, mortality and the rehabilitation costs for people with DM and DPN.

\section{Practice points:}

Patients with DM should be screened for DPN regularly and more frequently when they have developed tingling, pain, numbness and weakness in their feet and hands. Cognitive functions should be assessed in people with DM when they are screened for risk of falls.

Cognitive assessment of people with DM should be undertaken with a tool which can assess the relevant domains of cognition.

Balance assessment including tests of dynamic balance should be conducted on DPN patients.

If deficits in proprioception, vestibular function or lower extremity muscle strength in DPN are detected, it is important to test balance abilities and suggest measures to improve dynamic balance in order to prevent future falls.

Fall risk screening should be performed in people with DM especially of those with slower walking speed.
Lower limb isometric maximal muscle strength, fear of falling and the severity of neuropathy should be checked in people with DM in particular if they have a slow walking speed.

People with DM should be assessed for their lower limb muscle strength, especially if they have a history of falls. Foot deformities in people with DM should be screened regularly.

\section{Acknowledgements}

Research writing club organized by the Research Promotion and Facilitation Centre (RPFC), Faculty of Medicine, University of Colombo, Sri Lanka.

\section{Funding}

This review did not receive any specific grant from funding agencies in the public, commercial, or not-forprofit sectors.

\section{Contributors}

All authors contributed equally in conceptualization, writing, editing and reviewing of the manuscript.

\section{Competing interest}

Authors have no competing interests.

\section{References}

1. World Health Organization. Falls- fact sheet. 2019 Dec 30. Available from: https://www.who.int/newsroom/fact-sheets/detail/falls

2. World Health Organization. Diabetes- Fact sheets. 2019 Dec 30. Available from: https://www.who.int/news-room/fact-sheets/detail/diabetes

3. Sánchez Martínez M, Blanco A, Castell MV, Gutiérrez Misis A, González Montalvo JI, Zunzunegui MV, et al. Diabetes in older people: Prevalence, incidence and its association with medium- and long-term mortality from all causes. Aten Primaria. 2014;46(7):376-84. doi:10.1016/j.aprim.2013.12.004

4. Mustapa A, Justine M, Mustafah NM, Jamil N, Manaf H. Postural Control and Gait Performance in the Diabetic Peripheral Neuropathy: A Systematic Review. Biomed Res. Int. 2016;14p. Avalable from: https://www.hindawi.com/journals/bmri/2016/9305025/

5. Whiting DR, Guariguata L, Weil C, Shaw J. IDF diabetes atlas: global estimates of the prevalence of diabetes for 2011 and 2030. Diabetes Res Clin Pract. 2011;94(3):311-21. doi:10.1016/j.diabres.2011.10.029.

6. Pereira de Oliveira P, Fachin SM, Tozatti J, Ferreira MC, Marinheiro LPF, Comparative analysis of risk for falls in patients with and without type 2 diabetes mellitus. Rev Assoc Med Bras, 2012;58(2):234-9. doi:https://doi.org/10.1016/S2255-4823(12)70186-8

7. Schwartz AV, Hillier TA, Sellmeyer DE, Resnick HE, Gregg E, Ensrud KE, et al. Older Women With Diabetes Have a Higher Risk of Falls. A prospective study. Diabetes Care. 2002;25(10):1749-54. doi:10.2337/diacare.25.10.1749

8. Macgilchrist C, Paul L, Ellis BM, Howe TE, Kennon B, Godwin J. Lower-limb risk factors for falls in people with diabetes mellitus. Diabet Med. 2010;27(2):162-8.

doi:10.1111/j.1464-5491.2009.02914.x 
9. Tilling LM, Darawil K, Britton M. Falls as a complication of diabetes mellitus in older people. J Diabetes Complications. 2006;20(3):158-62. doi:https://doi.org/10.1016/j.jdiacomp.2005.06.004

10. Chiba Y, Kimbara Y, Kodera R, Tsuboi Y, Sato K, Tamura Y, et al. Risk factors associated with falls in elderly patients with type 2 diabetes. J Diabetes Complications. 2015;29(7):898-902.

doi:10.1016/j.jdiacomp.2015.05.016

11. Edwards JL, Vincent A, Cheng T, Feldman EL, Diabetic neuropathy: mechanisms to management. Pharmacol Ther. 2008;120(1):1-34. doi:10.1016/j.pharmthera.2008.05.005

12. Tesfaye S, Selvarajah D. Advances in the epidemiology, pathogenesis and management of diabetic peripheral neuropathy. Diabetes Metab Rev. 2012;28:8-14. 10.1002/dmrr.2239.

13. Vinik A, Casellini C, Nevoret ML, editors. Diabetic Neuropathies. Endotext [nternet]. South Dartmouth (MA): MDText.com, 2000. 2019 Dec 30.Available from: https://www.ncbi.nlm.nih.gov/sites/books/NBK279175/

14. Vinik AI, Mehrabyan A. Diabetic neuropathies. Med Clin North Am. 2004;88(4):947-99. doi:10.1016/j.mena.2004.04.009.

15. Richardson JK, Ching C, Hurvitz EA. The Relationship between Electromyographically Documented Peripheral Neuropatny and Falls. J Am Geriatr Soc. 1992;40(10):1008-12. doi:10.1111/j.15325415.1992.tb04477.x

16. Richardson JK, Hurvitz EA. Peripheral Neuropathy: A True Risk Factor for Falls. J Gerontol A Biol Sci Med Sci. 1995;50A(4):M211-M215. doi:https://doi.org/10.1093/gerona/50A.4.M211

17. Dingwell J, Ulbrecht J, Boch J, Becker MB, O'Gorman JT, Cavanagh PR. Neuropathic gait shows only trends towards increased variability of sagittal plane kinematics during treadmill locomotion. Gait Posture. 1999;10(1):21-29. doi:10.1016/s0966-6362(99)00016-8

18. Toosizadeh N, Mohler J, Armstrong DG, Talal TK, Najafi B, The Influence of Diabetic Peripheral Neuropathy on Local Postural Muscle and Central Sensory Feedback Balance Control. PLoS One, 2015;10(8):p. e0135255. doi: 10.1371/journal.pone.0135255

19. Brown SJ, Handsaker JC, Bowling FL, Maganaris CN, Boulton AJ, Reeves ND. Do patients with diabetic neuropathy use a higher proportion of their maximum strength when walking? J Biomech. 2014;47(15):p. 3639-44. doi:10.1016/j.jbiomech.2014.10.005

20. Hewston P, Deshpande N. Falls and Balance Impairments in Older Adults with Type 2 Diabetes: Thinking Beyond Diabetic Peripheral Neuropathy. Can J Diabetes. 2016;40(1):6-9. doi:10.1016/j.jcjd.2015.08.005

21. Dyck PJ, Giannini C. Pathologic alterations in the diabetic neuropathies of humans: a review. J Neuropathol Exp Neurol. 1996;55(12):1181-93. doi:10.1097/00005072-199612000-00001

22. Yagihashi S, Matsunaga M. Ultrastructural Pathology of Peripheral Nerves in Patients with Diabetic Neuropathy. Tohoku J Exp Med. 1979;129(4):357-66. doi:10.1620/tjem.129.357

23. Shern L, Chew RDGL. Clinical Endocrinology and Diabetes: An Illustrated Colour Text. 2006. Churchill Livingstone Elsevier.book.

24. Yagihashi S, Mizukami H, Sugimoto K. Mechanism of diabetic neuropathy: Where are we now and where to go? J. Diabetes Investig. 2011;2(1):18-32. doi:10.1111/j.2040-1124.2010.00070.x

25. Arkkila PE, Gautier JF. Musculoskeletal disorders in diabetes mellitus: an update. Best Pract Res Clin Rheumatol. 2003;17(6):945-70. doi:10.1016/j.berh.2003.11.001

26. Fernando DJ, Masson EA, Veves A, Boulton AJ. Relationship of Limited Joint Mobility to Abnormal Foot Pressures and Diabetic Foot Ulceration. Diabetes Care. 1991;14(1):8-11. doi:10.2337/diacare.14.1.8

27. Dyck PJ, Karnes JL, Daube J, O'Brien P, Service FJ. Clinical and neuropathological criteria for the diagnosis and staging of diabetic polyneuropathy. Brain. 1985;108(4):861-880. doi:10.1093/brain/108.4.861

28. Pham H, Armstrong DG, Harvey C, Harkless LB, Giurini JM, Veves A. Screening techniques to identify people at high risk for diabetic foot ulceration: a prospective multicenter trial. Diabetes Care. 2000;23(5):60611. doi:10.2337/diacare.23.5.606

29. Zis P, Sarrigiannis PG, Rao DG, Hewamadduma C, Hadjivassiliou M, Chronic idiopathic axonal polyneuropathy: a systematic review. J Neurol. 2016;263(10):1903-10. https://doi.org/10.1007/s00415-0168082-7

30. Mustapa A, Justine M, Mustafah NM, Jamil N, Manaf H. Postural Control and Gait Performance in the Diabetic Peripheral Neuropathy: A Systematic Review. BioMed Res. Int. 2016:p. 9305025-9305025. doi:https://doi.org/10.1155/2016/9305025

31. IJzerman TH, Schaper NC, Melai T, Meijer K, Willems PJ, Savelberg HH. Lower extremity muscle strength is reduced in people with type 2 diabetes, with and without polyneuropathy, and is associated with impaired mobility and reduced quality of life. Diabetes Res Clin Pract. 2012;95(3):345-51. doi:10.1016/j.diabres.2011.10.026.

32. Andersen H, Gadeberg PC, Brock B, Jakobsen J. Muscular atrophy in diabetic neuropathy: a stereological magnetic resonance imaging study. Diabetologia. 1997;40(9):1062-69.

doi:https://doi.org/10.1007/s001250050788 
33. Handsaker JC, Brown SJ, Bowling FL, Cooper G, Maganaris CN, Boulton AJ, et al. Contributory Factors to Unsteadiness During Walking Up and Down Stairs in Patients With Diabetic Peripheral Neuropathy. Diabetes Care. 2014;37(11):3047-3053. doi:10.2337/dc14-0955.

34. Cavanagh PR, Simoneau GG, Ulbrecht JS, Ulceration, unsteadiness, and uncertainty: The biomechanical consequences of diabetes mellitus. J Biomech. 1993;26:23-40. doi:https://doi.org/10.1016/00219290(93)90077-R

35. van Schie CHM, Vermigli C, Carrington AL, Boulton A. Muscle Weakness and Foot Deformities in Diabetes. Relationship to neuropathy and foot ulceration in Caucasian diabetic men, Diabetes Care, 2004;27(7):1668-73. doi:https://doi.org/10.2337/diacare.27.7.1668

36. Sacco ICN, Noguera GC; Tatiana Almeida Bacarin TA, Casarotto R, Tozzi FL, Alteração do arco longitudinal medial na neuropatia periférica diabética. Acta ortop. Bras. 2009;17:13-16. doi:https://doi.org/10.1590/S1413-78522009000100002

37. Walters DP, Gatling W, Hill RD, Mullee MA. The prevalence of foot deformity in diabetic subjects: A population study in an English community. Practical Diabetes Int. 1993;10(3):106-8. doi:https://doi.org/10.1002/pdi.1960100311

38. Anstey KJ, Sanden CV, Luszcz MA. An 8-Year Prospective Study of the Relationship Between Cognitive Performance and Falling in Very Old Adults. J Am Geriatr Soc. 2006;54(8):1169-76. doi:https://doi.org/10.1111/j.1532-5415.2006.00813.x

39. Holtzer R, Friedman R, Lipton RB, Katz M, Xue X, Verghese J. The relationship between specific cognitive functions and falls in aging. Neuropsychology. 2007;21(5):540-8. doi:10.1037/0894-4105.21.5.540

40. Buracchio TJ, Mattek N, Dodge HH, Hayes T, Pavel M, Howieson D. Executive function predicts risk of falls in older adults without balance impairment. BMC Geriatr. 2011;11(1):74. doi:10.1186/1471-2318-11-74

41. Eriksson S, Gustafson Y, Lundin-Olsson L. Risk factors for falls in people with and without a diagnose of dementia living in residential care facilities: A prospective study. Arch Gerontol Geriat. 2008;46(3):293-306. doi:10.1016/j.archger.2007.05.002

42. van Dijk PT, Meulenberg OG, van de Sande HJ, Habbema JD. Falls in Dementia Patients. Gerontologist. 1993;33(2):200-204. doi:10.1093/geront/33.2.200

43. Muir SW, Gopaul K, Odasso MMM. The role of cognitive impairment in fall risk among older adults: a systematic review and meta-analysis. Age Ageing. 2012;41(3):299-308. doi:10.1093/ageing/afs012.

44. Kawamura T, Umemura T, Hotta N. Cognitive impairment in diabetic patients: Can diabetic control prevent cognitive decline? J. Diabetes Investig. 2012;3(5):413-423. doi:10.1111/j.2040-1124.2012.00234.x

45. Reaven GM, Thompson LW, Nahum D, Haskins E. Relationship between hyperglycemia and cognitive function in older NIDDM patients. Diabetes Care. 1990;13(1):16-21. doi:10.2337/diacare.13.1.16

46. Munshi M, Capelson R, Grande L, Lin S, Hayes M, Milberg W, et al. Cognitive dysfunction is associated with poor diabetes control in older adults. Diabetes Care. 2006;29(8):1794-9. doi: 10.2337/dc06-0506

47. Messier C. Impact of impaired glucose tolerance and type 2 diabetes on cognitive aging. Neurobiol. Aging. 2005;26(Suppl 1):26-30. doi:10.1016/j.neurobiolaging.2005.09.014

48. Grodstein F, Chen J, Wilson RS, Manson JE. Type 2 diabetes and cognitive function in communitydwelling elderly women. Diabetes Care. 2001;24(6):1060-5. doi:10.2337/diacare.24.6.1060

49. Mooradian AD, Perryman K, Fitten J, Kavonian GD, Morley JE. Cortical function in elderly non-insulin dependent diabetic patients. Behavioral and electrophysiologic studies. Arch. Intern. Med., 1988;148(11):2369-72.

50. Fontbonne A, Berr C, Ducimetière P, Alpérovitch A. Changes in cognitive abilities over a 4-year period are unfavorably affected in elderly diabetic subjects: results of the Epidemiology of Vascular Aging Study. Diabetes Care. 2001;24(2):366-70. doi:https://doi.org/10.2337/diacare.24.2.366

51. Rucker JL, Jernigan SD, McDowd JM, Kluding PM. Adults with diabetic peripheral neuropathy exhibit impairments in multi-tasking and other executive functions. J Neurol Phys Ther. 2014;38(2):104-10. doi: 10.1097/NPT.0000000000000032.

52. Valkova M, Stamenov B, Peychinska D, Danovska M. Cognitive dysfunctions in diabetic polyneuropathy. Journal of IMAB. 2011;17(1):183-8. doi:10.5272/jimab.2011171.183

53. Moreira RO, Soldera AL, Cury B, Meireles C, Kupfer R. Is cognitive impairment associated with the presence and severity of peripheral neuropathy in patients with type 2 diabetes mellitus? Diabetol Metab Syndr. 2015;7(1):51. doi:10.1186/s13098-015-0045-0

54. Lord SR, Menz HB, Tiedemann A. A physiological profile approach to falls risk assessment and prevention. Phys Ther. 2003;83(3):237-52. doi:10.1093/ptj/83.3.237

55. Lord SR, Ward JA. Age-associated Differences in Sensori-motor Function and Balance in Community Dwelling Women. Age Ageing. 1994;23(6):452-60.

56. Vaz MM, Costa GC, Reis JG, Junior WM, Albuquerque de Paula FJ, Abreu DC. Postural Control and Functional Strength in Patients With Type 2 Diabetes Mellitus With and Without Peripheral Neuropathy. Arch. Phys. Med. Rehabil. 2013;94(12):2465-70. doi:10.1016/j.apmr.2013.06.007. 
57. DeMott TK, Richardson JK, Thies SB, Ashton-Miller JA. Falls and gait characteristics among older persons with peripheral neuropathy. Am J Phys Med Rehabil. 2007;86(2):125-32. doi:10.1097/PHM.0b013e31802ee1d1

58. Brown SJ, Handsaker JC, Bowling FL, Boulton AJ, Reeves ND. Diabetic Peripheral Neuropathy Compromises Balance During Daily Activities. Diabetes Care. 2015;38(6):1116-22. doi:10.2337/dc14-1982.

59. Dixit S, Maiya A, Shasthry BA, Kumaran DS, Guddattu V. Postural sway in diabetic peripheral neuropathy among Indian elderly. Indian J Med Res. 2015;142(6):713-20. doi:10.4103/0971-5916.174562

60. Lafond D, Corriveau H, Prince F. Postural Control Mechanisms During Quiet Standing in Patients With Diabetic Sensory Neuropathy. Diabetes Care, 2004;27(1):173-8. doi:10.2337/diacare.27.1.173

61. Chau RM, Ng TK, Kwan RL, Choi CH, Cheing GL. Risk of fall for people with diabetes. Disabil Rebabil, 2013;35(23):1975-80. doi:10.3109/09638288.2013.770079

62. Ghanavati T, Shaterzadeh Yazdi MJ, Goharpey S, Arastoo AA. Functional balance in elderly with diabetic neuropathy. Diabetes Res Clin Pract, 2012;96(1):24-8. doi:10.1016/j.diabres.2011.10.041.

63. Mueller MJ, Minor SD, Sahrmann SA, Schaaf JA, Strube MJ. Differences in the gait characteristics of patients with diabetes and peripheral neuropathy compared with age-matched controls. Phys Ther. 1994;74(4):299-308. doi:10.1093/ptj/74.4.299

64. Sawacha Z, Gabriella G, Cristoferi G, Guiotto A, Avogaro A, Cobelli C. Diabetic gait and posture abnormalities: A biomechanical investigation through three dimensional gait analysis. Clin Biomech. 2009;24(9):722-8. doi:10.1016/j.clinbiomech.2009.07.007

65. Shaw JE, van Schie CH, Carrington AL, Abbott CA, Boulton AJ. An analysis of dynamic forces transmitted through the foot in diabetic neuropathy. Diabetes Care. 1998;21(11):1955-1959. doi: https://doi.org/10.2337/diacare.21.11.1955

66. Menz HB, Lord SR, St George R, Fitzpatrick RC. Walking stability and sensorimotor function in older people with diabetic peripheral neuropathy. Arch Phys Med Rehabil. 2004;85(2):245-52. doi:10.1016/j.apmr.2003.06.015

67. Petrofsky J, Lee S, Bweir S. Gait characteristics in people with type 2 diabetes mellitus. Eur J Appl Physiol. 2005;93(5-6):640-7. doi:10.1007/s00421-004-1246-7

68. Allet L, Armand S, de Bie RA, Pataky Z, Aminian K, Herrmann FR, et al. Gait alterations of diabetic patients while walking on different surfaces. Gait Posture. 2009;29(3):488-93. doi:10.1016/j.gaitpost.2008.11.012.

69. Dingwell JB, Cavanagh PR. Increased variability of continuous overground walking in neuropathic patients is only indirectly related to sensory loss. Gait Posture. 2001;14(1):1-10. doi:10.1016/s0966-6362(01)00101-1

70. Allet L, Armand S, de Bie RA, Golay A, Pataky Z, Aminian K, et al. Clinical factors associated with gait alterations in diabetic patients. Diabet Med. 2009;26(10):1003-9.

doi:10.1111/j.1464-5491.2009.02811.x. 